Check for updates

Cite this: RSC Adv., 2019, 9, 13048

\title{
Construction of a luminescent sensor based on a lanthanide complex for the highly efficient detection of methyl parathion $\uparrow$
}

\author{
Xuan Hu, ${ }^{a}$ Fengyi Wang, ${ }^{a}$ Qianqian Peng, ${ }^{a}$ Jing Hu, ${ }^{a}$ Huaqiao Peng, ${ }^{c}$ Lin $\mathrm{Li}^{,}{ }^{\mathrm{c}}$ \\ Baozhan Zheng, (D)*ab Juan Du (D) *ab and Dan Xiao ${ }^{\text {ab }}$
}

\begin{abstract}
A highly sensitive and selective luminescent sensor for the detection of methyl parathion (MP) pesticide was described in this study. The target molecule HL was synthesized by modifying the structure of 4hydroxybenzlidene imidazolinone ( $\mathrm{HBI}$ ) with nitrogen-containing heterocyclic 1,10-phenanthroline. In the presence of $\mathrm{Eu}^{3+}, \mathrm{a} \mathrm{HL}-\mathrm{Eu}^{3+}$ complex was formed which could emit strong red fluorescence due to the removal of coordinated water molecules and an intramolecular energy transfer from $\mathrm{HL}$ to $\mathrm{Eu}^{3+}$. Addition of MP into the strongly fluorescent solution of $\mathrm{HL}-\mathrm{Eu}^{3+}$ induced quenching of the complex's fluorescence, and this quenching behavior occurred because of the competition coordination of MP and $\mathrm{HL}$ for $\mathrm{Eu}^{3+}$. A calibration curve was developed that related the extent of fluorescence quenching to MP concentration, making the $\mathrm{HL}-\mathrm{Eu}^{3+}$ system a sensitive and selective fluorescent sensor for MP. Under the experimental conditions, the detection limit for MP was down to $95 \mathrm{nM}$ based on LOD $=3 \sigma / \mathrm{S}$. Moreover, the fluorescence assay developed here allowed the detection of MP in two different types of real samples including pond water and pear juice, and satisfactory results demonstrate that this fluorescent sensor based on $\mathrm{HL}-\mathrm{Eu}^{3+}$ has potential application in environment and food analysis.
\end{abstract}

Received 7th March 2019 Accepted 13th April 2019

DOI: 10.1039/c9ra01748h

rsc.li/rsc-advances develop more rapid, simple and accurate methods for the determination of OPs with higher sensitivity and selectivity. As a widely used strategy, the fluorescent sensors have aroused considerable attention due to their advantages of excellent sensitivity and selectivity, short-time data acquisition, facile manipulations, low cost and visual detection properties. Therefore, a number of fluorescent sensors based on organic fluorophores, Au nanoparticles, quantum dots and carbon dots et al. have been constructed for the detection of OPs in real samples. ${ }^{14-18}$ Barba-Bon and co-workers designed two $\mathrm{Eu}^{3+}$ and $\mathrm{Au}^{3+}$ complexes based on commonly used organic fluorophore BODIPY. The BODIPY-containing complexes can effectively detect V-type nerve agent surrogates, demeton-S, by a colorimetric and fluorescent double-detection assay with high sensitivity and selectivity. The displacement of BODIPY ligand by demeton-S from the metallic centre resulted in obvious colour change and fluorescence quenching of the detecting system. The detection limit for demeton-S reached as low as 9 ppm. ${ }^{19}$ $\mathrm{Wu}$ and co-workers used carbon dots as fluorescent probe for the determination of paraoxon. The fluorescence emission intensity of CDs decreased significantly in the presence of AuNPs via fluorescence resonance energy transfer (FRET). Upon addition of acetylthiocholine (ATC) and butyrylcholinesterase (BChE), the fluorescence was recovered because the thiocholine generated by enzymatic catalysis reaction caused the aggregation of Au NPs. Furthermore, the fluorescence was quenched again by paraoxon through the inhibition effect on the activity 
of BChE. Therefore, a facile FRET sensing platform for OPs was constructed. ${ }^{20}$

The ideal fluorescent probe should have the advantages of controllable fluorescence, good stability, fast response, high selectivity and sensitively. When applied to environmental analysis, it should also have favorable water solubility and nonpolluting characteristics and function independently of environmental factors and interferences. Lanthanide elements have special luminescence features and excellent coordination properties. $^{21,22}$ Compared to other fluorescent systems, lanthanide fluorescent complexes also have the advantages of high fluorescence quantum yield, large Stokes shift, adjustable photophysical and photochemical characteristics, good stability, narrow emission peaks and long fluorescence lifetime. $^{23,24}$ Therefore, lanthanides has become an alternative to organic fluorophores especially in considering of background autofluorescence interference. If an analyte can act as a competitive binder for the lanthanide ion center in the luminescent Ln-containing complex, then it has the ability to 'switch off' the lanthanide emission. In particular, the excellent abilities of $\mathrm{Eu}^{3+}$ to selectively interact with the phosphate group in OPs coupled with favourable photophysical characteristics make the luminescent Eu-containing complexes attractive choices for the detection of organophosphorus compounds. Knapton and co-workers prepared some fluorescent organometallic sensors for the detection of chemical-warfare-agent (CWA) mimics by a displacement assay. In this work, several ligands based on a 2,6-bis(1'-methylbenzimidazolyl)pyridine (Mebip) structure was developed. The complexation of Mebip with $\mathrm{Eu}^{3+}$ in a $1: 1$ ligand/ $\mathrm{Eu}^{3+}$ ratio resulted in a strong luminescence emission. The addition of triethyl phosphate (TEP) to the solution of $\mathrm{Eu}^{3+}$-Mebip complex led to the complete and immediate quenching of the characteristic red luminescence of $\mathrm{Eu}^{3+} .^{25}$ Zhang and co-workers immobilized Mebip onto poly(ethylene-glycol)-grafted polystyrene micro-spheres, and the following incorporation of $\mathrm{Eu}^{3+}$ ions resulted in luminescent microspheres. Upon addition of diethyl chlorophosphate (DCP), the luminescence of the microspheres was immediately quenched. These results indicated that even be immobilized on a solid substrate, some ligands for Ln were still able to be effectively displaced by organophosphorus compounds. ${ }^{26}$ However, direct excitation of lanthanide ions to luminesce is difficult because the $\mathrm{f}-\mathrm{f}$ transitions are Laporte-forbidden, thus some light-harvesting ligands called 'antenna ligands' are necessary to absorb and transfer the exciting energy to lanthanide ions. ${ }^{27,28}$ For light conversion systems based on $\mathrm{Ln}^{3+}$ ions, the main requirements are high ligand-absorption coefficients, efficient ligand-to-metal energy transfer and minimal nonradiative deactivation of the excited state of the metal. ${ }^{29}$ Encapsulation of the $\mathrm{Ln}^{3+}$ ion by polydentate/macrocyclic ligands, ${ }^{30}$ Schiff bases,${ }^{31}$ organic acids, ${ }^{32}$ and even proteins is the most common strategy employed to satisfy these criteria. ${ }^{33}$ As one of the most toxic OPs, methyl parathion (O,O-dimethyl $O$ 4-nitrophenyl phosphorothionate, MP, Scheme 1(a)) was classified as 'Category Ia' (extremely toxic) by the World Health Organization (WHO) and 'Toxicity Category I' (most toxic) by the United States Environmental Protection Agency (USEPA). ${ }^{34-36}$

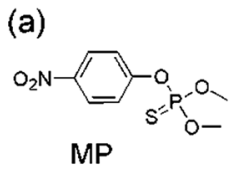

(b)
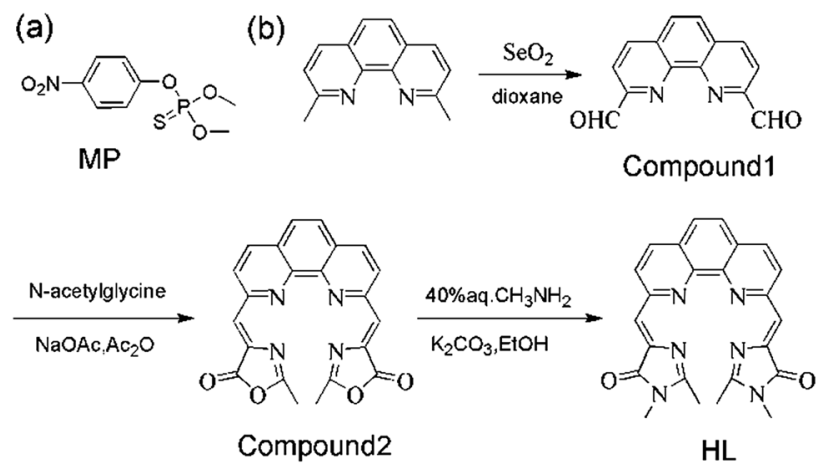

Scheme 1 (a) The structure of MP; (b) synthesis of Compound 1, Compound 2 and $\mathrm{HL}$.

However, its detection by fluorescent methods was seldom reported, and almost all of them utilized enzymes as catalyst, ${ }^{37,38}$ which made the analytical process complex and expensive. Based on the above analysis, herein, a luminescent lanthanide complex of $\mathbf{H L}-\mathbf{E u}^{3+}$ with red fluorescent emission was synthesized and chosen as the sensing and detecting units for MP. The aromatic cyclic polyamine ligand HL was designed and synthesized by modifying the structure of 4-hydroxybenzlidene imidazolinone (HBI) with nitrogen-containing heterocyclic 1,10-phenanthroline, as shown in Scheme 1(b). HL itself had very weak fluorescence in solution. With the addition of $\mathrm{Eu}^{3+}$, HL can act as an effective 'antenna ligand' to coordinate with $\mathrm{Eu}^{3+}$ and form a complex $\mathbf{H L}-\mathbf{E u}^{3+}$ with the characteristic emission of $\mathrm{Eu}^{3+}$. We foresaw that the $\mathrm{Eu}^{3+}$ emission of $\mathbf{H L}-\mathbf{E u}^{3+}$ could be 'switched off' through the displacement of the HL antenna in the presence of MP caused by the preferable interaction between $\mathrm{Eu}^{3+}$ and $\mathbf{M P}$, therefore, an effective MP sensor can be successfully constructed.

\section{Experimental section}

\section{Apparatus}

${ }^{1} \mathrm{H}$ NMR and ${ }^{13} \mathrm{C}$ NMR were measured on a BrukerAVII-400 MHz spectrometer with chemical shifts reported in ppm (in DMSO; TMS as internal standard). Mass spectra were obtained from a commercial ion trap mass spectrometer (Thermo Fisher Scientific, San Jose, CA). Thermo Scientific Nicolet 6700 FT-IR spectrometer (Sugar Land, TX, USA) was used to record the FT-IR of HL. Fluorescence spectra were determined on F-7000 spectrophotometer equipped with a $1 \mathrm{~cm}$ quartz cell (HITA$\mathrm{CHI}$, Japan). UV-visible measurements were measured on U2900 spectrophotometer (HITACHI, Japan).

\section{Materials reagents}

Europium(III) chloride hexahydrate $\left(\mathrm{EuCl}_{3} \cdot 6 \mathrm{H}_{2} \mathrm{O}\right), 2$,9-dimethyl1,10-phenanthroline, $N$-acetylglycine (AR) were obtained from Alfa Aesar; selenium dioxide was purchased from SigmaAladdin; sodium acetate, acetic anhydride and ethanol were purchased from Kelong Chemical Reagent Co., Ltd. (Chengdu, China); methyl parathion (MP) was purchased from shanghai Macklin Biochemical Co., Ltd. All chemicals and reagents were 
of analytical grade and used without further purification. Double distilled water was employed for all experiments.

\section{Synthesis of Compound 1}

In this paper, HL and its intermediates (Compound 1, Compound 2) were synthesized via simple steps as depicted in Scheme 1(b). Typically, 2,9-dimethyl-1,10-phenanthroline (1.0 g, $4.60 \mathrm{mmol})$, selenium dioxide $(2.5 \mathrm{~g}, 22.5 \mathrm{mmol})$ were dissolved in 1,4-dioxane ( $35 \mathrm{~mL}$ ) and stirred at $110^{\circ} \mathrm{C}$ for $2 \mathrm{~h}$. The formed precipitate was separated with diatomite thermal filtration and then recrystallized in $\mathrm{DMF} / \mathrm{H}_{2} \mathrm{O}$ with vacuum dried at $40{ }^{\circ} \mathrm{C}$ for $12 \mathrm{~h}$. Thus, $0.70 \mathrm{~g}$ (yield 67.6\%) yellow solid Compound 1 could be obtained. Compound 1: ${ }^{1} \mathrm{H}$ NMR (400 MHz, DMSO- $d_{6}$ ) $\delta_{\mathrm{H}}$ (ppm): 10.31 (CHO, s, 2H), 8.71 (Ar-H, d, $J=8.2 \mathrm{~Hz}, 2 \mathrm{H}), 8.40$ $(\mathrm{Ar}-\mathrm{H}, \mathrm{d}, J=8.4 \mathrm{~Hz}, 2 \mathrm{H}), 8.19(\mathrm{Ar}-\mathrm{H}, \mathrm{d}, J=4.0 \mathrm{~Hz}, 2 \mathrm{H})$. (Fig. S1†) ${ }^{13} \mathrm{C}$ NMR (400 MHz, DMSO) $\delta_{\mathrm{C}}(\mathrm{ppm}): 194.01,152.3,148.6$, 138.2, 129.7, 120.6. (Fig. S2†).

\section{Synthesis of Compound 2}

For the synthesis of Compound 2, Compound 1 (0.67 g, 3 $\mathrm{mmol})$, anhydrous sodium acetate $(0.5 \mathrm{~g}, 6 \mathrm{mmol})$, and $\mathrm{N}$-acetylglycine $(0.73 \mathrm{~g}, 6 \mathrm{mmol})$ were dissolved in $30 \mathrm{~mL}$ acetic anhydride refluxed at $90{ }^{\circ} \mathrm{C}$ for $4 \mathrm{~h}$. When the mixture was cooled down to room temperature, $250 \mathrm{~mL}$ cold water was added into the solution and yellow precipitate could be formed quickly. After the filtration, washing with cold ethanol and vacuum-drying at $60{ }^{\circ} \mathrm{C}$ for $12 \mathrm{~h}$, a yellow solid compound of Compound 2 could be obtained (0.49 g, yield $41.9 \%)$. Compound 2: ${ }^{1} \mathrm{H}$ NMR (400 MHz, DMSO- $\left.d_{6}\right) \delta_{\mathrm{H}}(\mathrm{ppm}): 8.89(\mathrm{Ar}-$ $\mathrm{H}, \mathrm{d}, J=8.1 \mathrm{~Hz}, 2 \mathrm{H}), 8.83(\mathrm{Ar}-\mathrm{H}, \mathrm{d}, J=8.2 \mathrm{~Hz}, 2 \mathrm{H}), 8.38(\mathrm{C}=$ $\mathrm{CH}, \mathrm{s}, 2 \mathrm{H}), 8.30(\mathrm{Ar}-\mathrm{H}, \mathrm{m}, 2 \mathrm{H}), 1.83\left(\mathrm{CH}_{3}, \mathrm{~s}, 6 \mathrm{H}\right)$, (Fig. S3†).

\section{Synthesis of HL}

Compound 2 (0.49 g, $1.2 \mathrm{mmol})$, potassium carbonate (0.1 g, $0.72 \mathrm{mmol}$ ) and $1 \mathrm{~mL} 40 \%$ aqueous methylamine solution were dissolved in $20 \mathrm{~mL}$ ethanol and stirred at $90{ }^{\circ} \mathrm{C}$ for $4 \mathrm{~h}$. After cooling down to room temperature, the mixture was diluted with $100 \mathrm{~mL}$ water, the $\mathrm{pH}$ of the solution was adjusted to 3.0 with concentrated $\mathrm{HCl}$, and left overnight at $4{ }^{\circ} \mathrm{C}$ in refrigerator. The formed yellow precipitate was then filtered, washed and dried. The obtained crude compound was purified by thin layer chromatography with chloroform/ethylacetate $(1: 3, \mathrm{v} / \mathrm{v})$, thus, a pure compound of HL (yellow solid (25\%)) was synthesized, which was then used for the characterization of FT-IR, ESI-MS and ${ }^{1} \mathrm{H}$ NMR. HL: ${ }^{1} \mathrm{H}$ NMR (400 MHz, DMSO- $\left.d_{6}\right) \delta_{\mathrm{H}}(\mathrm{ppm})$ : 8.64-8.38 (Ar-H, d, $J=7.2 \mathrm{~Hz}, 2 \mathrm{H}), 8.32-7.9(\mathrm{Ar}-\mathrm{H}, \mathrm{d}, J=7.0 \mathrm{~Hz}$, $2 \mathrm{H}), 7.68(\mathrm{C}=\mathrm{CH}, \mathrm{s}, 2 \mathrm{H}), 7.54(\mathrm{Ar}-\mathrm{H}, \mathrm{d}, J=8.2 \mathrm{~Hz}, 2 \mathrm{H}), 3.75(\mathrm{~N}-$ $\left.\mathrm{CH}_{3}, \mathrm{~s}, 6 \mathrm{H}\right), 2.07\left(\mathrm{~N}=\mathrm{C}-\mathrm{CH}_{3}, \mathrm{~s}, 6 \mathrm{H}\right)$, (Fig. S4 $\dagger$ ). The ESI-MS data of HL showed a peak with $m / z 463.0298\left([\mathbf{H L}+\mathrm{K}]^{+}\right)$(Fig. S5 $\dagger$ ). The addition of $\mathrm{Eu}^{3+}$ resulted in the formation of $\mathbf{H L}-\mathbf{E u}^{3+}$ complex, and the MALDI-TOF MS data of $\mathbf{H L}-\mathbf{E u}^{3+}$ showed a peak with $m / z 629.1\left(\left[\mathbf{H L}-\mathbf{E u}^{3+}+3 \mathrm{H}_{2} \mathrm{O}-2 \mathrm{H}\right]^{+}\right)$cal.: 629.1 found 629.1 (Fig. S6 $\dagger$ ). The MALDI-TOF MS data of $\mathrm{Eu}^{3+}$ with the presence of MP has been added and the peak with $\mathrm{m} / \mathrm{z} 581.3$ in Fig. $\mathrm{S} 7 \uparrow$ is assigned to $\left[\mathrm{Eu}+\mathbf{M P}+\mathrm{K}+7 \mathrm{H}_{2} \mathrm{O}\right]^{4+}$ (cal.: 581.0 found 581.3).

\section{Detection procedure of methyl parathion}

HL stock solution ( $0.3 \mathrm{mM})$ was prepared in Tris-HCl buffer $(\mathrm{pH}$ $7.0,25 \mathrm{mM}$ ) and further diluted to $60 \mu \mathrm{M}$ for the assay. The fluorescence spectra were then measured with an excitation wavelength $\left(\lambda_{\text {ex }}\right)$ of $356 \mathrm{~nm}$, and the fluorescence spectrum of $\mathbf{H L}-\mathbf{E u}^{3+}$ solution was recorded between 600-650 $\mathrm{nm}$ with a maximum emission wavelength of $617 \mathrm{~nm}\left(\lambda_{\mathrm{em}}\right)$. All of the fluorescence intensity measurements were conducted in triplicate. Three polluted water samples were collected from a pond nearby and filtered prior to analysis. All the stock solutions were stored at $4{ }^{\circ} \mathrm{C}$ in a refrigerator until use.

\section{Results and discussion}

\section{Design and characterization of $\mathrm{HL}-\mathrm{Eu}^{3+}$}

In order to obtain a fluorescent system with excellent performance, the fluorescence behavior of HL toward several lanthanide metal ions were firstly examined in Tris-HCl buffer $(\mathrm{pH}$ 7.0, $25 \mathrm{mM}$ ). As shown in Fig. 1(A), excepting the comparatively stable and weak fluorescence peak of HL at $460 \mathrm{~nm}$, there was no characteristic fluorescence emission of any one of the lanthanide metal ions including $\mathrm{La}^{3+}, \mathrm{Nd}^{3+}, \mathrm{Tb}^{3+}, \mathrm{Yb}^{3+}, \mathrm{Er}^{3+}$ and $\mathrm{Ce}^{3+}$ that can be detected when they were introduced into $\mathbf{H L}$ solution. In comparison, the fluorescence spectrum changed immediately upon $\mathrm{Eu}^{3+}$ addition and the characteristic peaks of $\mathrm{Eu}^{3+}$ at $581 \mathrm{~nm}, 593 \mathrm{~nm}$ and $617 \mathrm{~nm}$ appeared. This result demonstrated that $\mathrm{Eu}^{3+}$ can coordinate with $\mathbf{H L}$, which could transfer the absorbed energy to $\mathrm{Eu}^{3+}$ ions to excite them. The coordination process of $\mathrm{Eu}^{3+}$ with $\mathbf{H L}$ was displayed in Scheme 2(a). In order to explore the optimal concentration of $\mathrm{Eu}^{3+}$ in $\mathbf{H L}-\mathbf{E u}^{3+}$ system, we analyzed the fluorescence intensity of $\mathbf{H L}-$ $\mathbf{E u}^{3+}$ with different amounts of $\mathrm{Eu}^{3+}$. As shown in Fig. S8, $\uparrow$ the emission intensity at $617 \mathrm{~nm}$ increased gradually with continuous addition of $\mathrm{Eu}^{3+}$, then reached the highest level upon addition of $60 \mu \mathrm{M} \mathrm{Eu}^{3+}$. Nevertheless, an obvious fluorescence decrease was appeared when the concentration of $\mathrm{Eu}^{3+}$ is higher than $60 \mu \mathrm{M}$. Therefore, $60 \mu \mathrm{M} \mathrm{Eu}^{3+}$ was selected as the ideal concentration and used in following experiments. Importantly, the maximal fluorescence intensity of $\mathbf{H L}-\mathbf{E u}^{3+}$ was remained nearly steady with constant light irradiation $(356 \mathrm{~nm})$ for $2 \mathrm{~h}$, and the unchanged intensity proved its excellent photo-stability
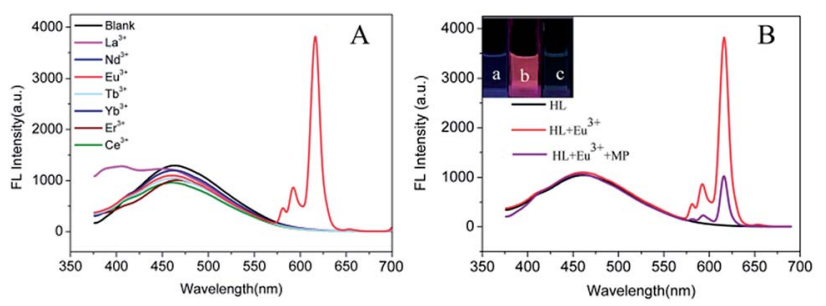

Fig. 1 (A) Fluorescence spectra of $\mathrm{HL}$ upon addition of different lanthanide metal ions $(60 \mu \mathrm{M})$ of $\mathrm{La}^{3+}, \mathrm{Nd}^{3+}, \mathrm{Eu}^{3+}, \mathrm{Tb}^{3+}, \mathrm{Yb}^{3+}, \mathrm{Er}^{3+}$ and $\mathrm{Ce}^{3+}$ with an excitation wavelength of $356 \mathrm{~nm}$. (B) Fluorescence spectra of $\mathrm{HL}$, next adding $\mathrm{Eu}^{3+}$ and then adding $20 \mu \mathrm{M}$ MP. Inset: photograph of $\mathrm{HL}(\mathrm{a}), \mathrm{HL}-\mathrm{Eu}^{3+}$ (b), and $\mathrm{HL}-\mathrm{Eu}^{3+}+\mathrm{MP}$ (c). 


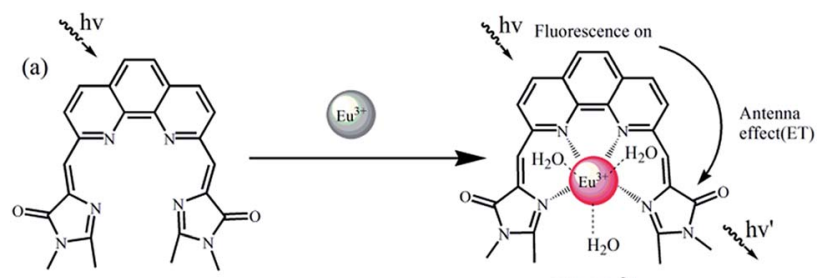

$\mathrm{HL}$

(b)

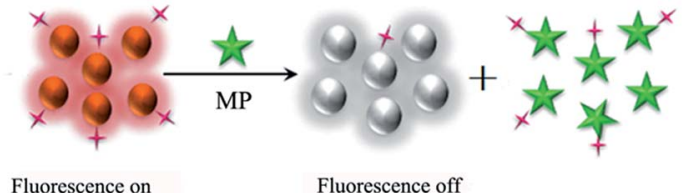

$+: \mathrm{HL}_{-\mathrm{Eu}^{3+}}$

( $\mathrm{HL}+\mathrm{Eu}^{3+}$

«: MP

Scheme 2 (a) The coordination process of $\mathrm{Eu}^{3+}$ with $\mathrm{HL}$. (b) The schematic representation of the fluorescent sensing mechanism for MP determination based on $\mathrm{HL}-\mathrm{Eu}^{3+}$

and expectable application potential as an ideal sensor used in complex environment systems (Fig. S9†).

To understand the stoichiometric nature of $\mathbf{H L}-\mathbf{E u}^{3+}$, the Job's plot for the binding activity between $\mathbf{H L}$ and $\mathrm{Eu}^{3+}$ was studied, and the result exhibited 1:1 stoichiometry from the fluorescence titration (Fig. S10 $\dagger$ ). The FT-IR spectra of HL and HL-Eu ${ }^{3+}$ were reported in Fig. S11. $\dagger$ From which, the characteristic peaks at about $1630 \mathrm{~cm}^{-1}, 1660 \mathrm{~cm}^{-1}$ and $3320 \mathrm{~cm}^{-1}$ should be attributed to the stretching vibration of $\mathrm{C}=\mathrm{N}, \mathrm{C}=\mathrm{O}$ and $\mathrm{N}-\mathrm{H}$ of $\mathbf{H L}$, respectively. Compared with the peaks of $\mathbf{H L}$ (1347 $\mathrm{cm}^{-1}$ and $1630 \mathrm{~cm}^{-1}$ for $\mathrm{C}-\mathrm{N}$ and $\mathrm{C}=\mathrm{N}$ groups, respectively), the slight peak shifts $\left(1319 \mathrm{~cm}^{-1}\right.$ and $\left.1610 \mathrm{~cm}^{-1}\right)$ in $\mathbf{H L}-$ $\mathbf{E u}^{3+}$ suggested that the $\mathrm{N}$ atoms in both of the $\mathrm{C}-\mathrm{N}$ and $\mathrm{C}=\mathrm{N}$ groups were involved in the coordination with $\mathrm{Eu}^{3+}$ in the formation of $\mathbf{H L}-\mathbf{E u}^{3+}$ complex. In addition, the Eu-N stretching vibration was observed at $479 \mathrm{~cm}^{-1}$ in $\mathbf{H L}-\mathbf{E u}^{3+}$. The strong and wide stretching vibration peak of $\mathrm{O}-\mathrm{H}$ bond at about $3349 \mathrm{~cm}^{-1}$ in $\mathbf{H L}-\mathbf{E u}^{3+}$ could be assigned to the comprised water molecules of $\mathrm{Eu}^{3+}$. On the basis of the above analysis, the conclusion can be reached that $\mathbf{H L}-\mathbf{E u}^{3+}$ has been formed.

The fluorescence spectra of $\mathbf{H L}-\mathbf{E u}^{3+}$ in the presence of MP were measured in Tris-HCl buffer ( $\mathrm{pH}$ 7.0, $25 \mathrm{mM})$. As illustrated in Fig. 1(B), comparing the fluorescent emission at $460 \mathrm{~nm}$ with $\mathbf{H L}$ alone, $\mathbf{H L}-\mathbf{E u}^{3+}$ revealed an extra strong characteristic emission center at $617 \mathrm{~nm}$ when excited at $356 \mathrm{~nm}$ with a fluorescent color change from weak blue to bright red (inset of Fig. 1(B)). With the addition of $20 \mu \mathrm{M}$ MP into the solution of $\mathbf{H L}-\mathbf{E u}^{3+}$, the complex's fluorescence was obviously quenched and the change was easily discernible to the naked eye under UV light irradiation as Fig. 1(B) inset showed. Moreover, the fluorescent response time of $\mathbf{H L}-\mathbf{E u}^{3+}$ toward MP was also investigated in this work. The results showed that when MP was added to $\mathbf{H L}-\mathbf{E u}^{3+}$ solution, about $70 \%$ fluorescence intensity quench was detected at $617 \mathrm{~nm}$ within one minute and the fluorescent intensity remained almost constant in around $10 \mathrm{~min}$ (Fig. S12 $\dagger$ ). Therefore, all the fluorescent spectra measurement in this work are carried out after the addition of
MP for 10 minutes. These facts made the sensor $\mathbf{H L}-\mathbf{E u}^{3+}$ the potential candidate for effectively detecting MP.

\section{Investigation of the experimental conditions}

In order to explore the influence of $\mathrm{pH}$ on the performance of $\mathbf{H L}-\mathbf{E u}^{3+}$ towards MP determination, the response of constructed fluorescent assay $\mathrm{pH}$ condition was further optimized by the addition of various Tris- $\mathrm{HCl}$ buffer at $\mathrm{pH} 2.0-11.0$ (Fig. 2(A)). The measured results revealed that the fluorescence intensity of $\mathbf{H L}-\mathbf{E u}^{3+}$ increased gradually to a maximum value with the increase of $\mathrm{pH}$ until $\mathrm{pH} 7.0$ and then slowly decreased. With the presence of MP, it can be observed that the fluorescence quenching efficiency was affected by the $\mathrm{pH}$ value, and a maximum quenching rate was obtained at $\mathrm{pH}$ 7.0. Hence, $\mathrm{pH}$ 7.0 was employed as the favorable $\mathrm{pH}$ value. Furthermore, the fluorescence intensity of $\mathbf{H L}-\mathbf{E u}^{\mathbf{3}^{+}}$with or without $\mathbf{M P}$ was comparatively satisfactory stability even in a salty medium with a $\mathrm{NaCl}$ concentration as high as $0.1 \mathrm{M}$ (Fig. 2(B)), indicating its potential applicability in complex water environmental samples analysis.

\section{Specificity of $\mathrm{HL}-\mathrm{Eu}^{3+}$ for MP detection}

To examine the selectivity of $\mathbf{H L}-\mathbf{E u}^{3+}$ for $\mathbf{M P}$ detection, we investigated the fluorescence behavior of $\mathbf{H L}-\mathbf{E u}^{3+}$ to commonly existent organic pollute compounds (OPCs), anions and metal ions (Fig. 3 and S13†), including $p$-nitrotoluene, 2,4,6-trinitrotoluene, $o$-cresol, phenol, 2,5-dimethylphenol, resorcinol, carbaryl, phoxim, triethylphosphate, dimethoate, $\mathrm{PO}_{4}{ }^{3-}$, $\mathrm{HPO}_{4}{ }^{2-}, \mathrm{H}_{2} \mathrm{PO}_{4}{ }^{-}, \mathrm{SO}_{4}{ }^{2-}, \mathrm{F}^{-}, \mathrm{Br}^{-}, \mathrm{NO}_{3}{ }^{-}, \mathrm{Ac}^{-}, \mathrm{Ba}^{2+}, \mathrm{Mg}^{2+}, \mathrm{Ca}^{2+}$, $\mathrm{Hg}^{2+}, \mathrm{Na}^{+}, \mathrm{Fe}^{3+}, \mathrm{Pb}^{2+}, \mathrm{Cd}^{2+}, \mathrm{Zn}^{2+}$ and MP. Negligible fluorescence intensity changes were observed upon the addition of the above mentioned substances except MP (Fig. 3 blank bars, Fig. S13A $\dagger$ ). Another important feature of $\mathbf{H L}-\mathbf{E u}^{3+}$ was its high selectivity toward MP in a competitive environment. The competitive experiments were conducted in coexist of MP and excess amount of various other OPCs, metal ions and anions (Fig. 3 red bars, Fig. S13B $\dagger$ ). There were no distinct variations of the fluorescence signal caused by the co-existence of these potential interrupting species. The absorption spectra of HL$\mathbf{E u}^{3+}$ with the addition of as-mentioned OPs (carbaryl, phoxim, triethyl phosphate, dimethoate and MP) helped to explain the
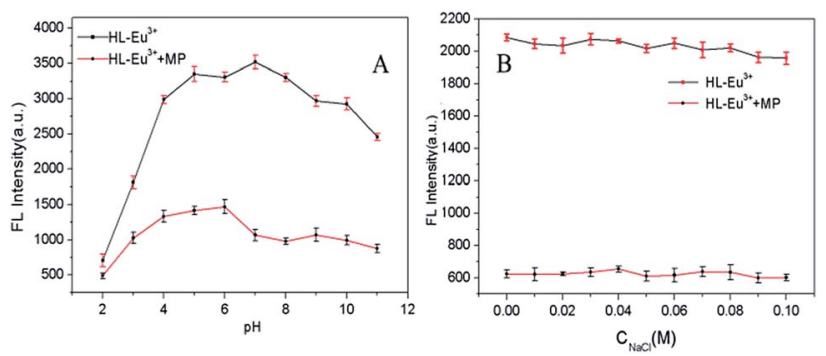

Fig. 2 (A) Effect of the $\mathrm{pH}$ on the fluorescence intensity of $\mathrm{HL}-\mathrm{Eu}^{3+}$ with (red line) and without (black line) MP. (B) Effect of the concentration of $\mathrm{NaCl}$ on the fluorescence intensity of $\mathrm{HL}-\mathrm{Eu}^{3+}$ with (red line) or without (black line) MP. 


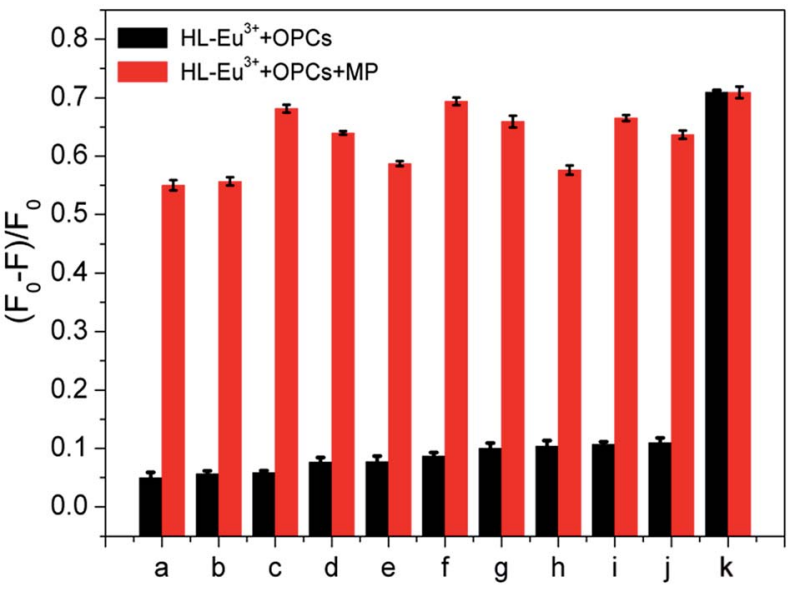

Fig. 3 The fluorescence intensity of $\mathrm{HL}-\mathrm{Eu}^{3+}$ in the presence of various organic pollute compounds (OPCs). The black bars represent the addition of excess OPCs. The red bars represent the subsequent addition of MP $(20 \mu \mathrm{M})$. (a) $p$-Nitrotoluene $(200 \mu \mathrm{M})$, (b) 2,4,6-trinitrotoluene $(200 \mu \mathrm{M})$, (c) o-cresol $(25 \mu \mathrm{M})$, (d) phenol $(200 \mu \mathrm{M})$, (e) 2,5dimethylphenol $(200 \mu \mathrm{M})$, (f) resorcinol $(100 \mu \mathrm{M})$, (g) carbaryl $(200 \mu \mathrm{M})$, (h) phoxim $(100 \mu \mathrm{M})$, (i) triethyl phosphate $(200 \mu \mathrm{M})$, (j) dimethoate $(200 \mu \mathrm{M})$, (k) MP $(20 \mu \mathrm{M})$.
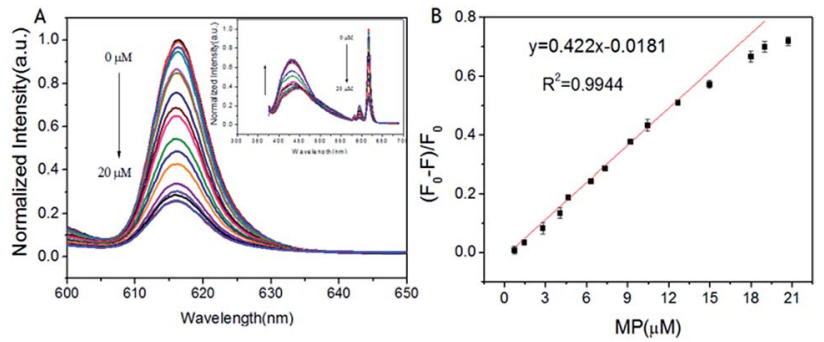

Fig. 4 (A) Fluorescence emission spectra of $\mathrm{HL}-\mathrm{Eu}^{3+}$ were measured upon addition of increasing concentrations of MP. (B) The fluorescence intensity at $617 \mathrm{~nm}$ of $\mathrm{HL}-\mathrm{Eu}^{3+}$ was linearly related to the concentration of MP

Table 1 Determination of MP in spiked real samples

\begin{tabular}{lllcl}
\hline Sample & $\begin{array}{l}\text { Added } \\
(\mu \mathrm{M})\end{array}$ & Found $(\mu \mathrm{M})$ & Recovery $(\%)$ & $\begin{array}{l}\text { RSD }(n \\
=3 \%)\end{array}$ \\
\hline Pond water & 2.00 & 2.13 & 106.62 & 3.28 \\
& 4.00 & 3.96 & 99.15 & 2.53 \\
Pear juice & 6.00 & 5.84 & 97.37 & 1.78 \\
& 2.00 & 2.06 & 102.82 & 2.97 \\
& 4.00 & 4.06 & 101.51 & 1.08 \\
& 6.00 & 5.95 & 96.23 & 2.68
\end{tabular}

observed selectivity of $\mathbf{H L}-\mathbf{E u}^{3+}$ toward MP. As displayed in Fig. S14, $\dagger$ HL-Eu ${ }^{3+}$ had two distinct absorption bands centred at $232 \mathrm{~nm}$ and $282 \mathrm{~nm}$, respectively. The addition of MP induced an obvious disappearance of the absorption band centred at $232 \mathrm{~nm}$ and a minor blue-shift from $282 \mathrm{~nm}$ to $280 \mathrm{~nm}$. Otherwise, there was no apparent change of the absorption bands of $\mathbf{H L}-\mathbf{E u}^{3+}$ with the presence of other OPs except MP.
Therefore, it can be reasonably presumed that only the addition of MP can break the combination between $\mathbf{H L}$ and $\mathrm{Eu}^{3+}$ and induce the displacement of $\mathbf{H L}$ from $\mathbf{H L}-\mathbf{E u}^{3+}$ complex. These results clearly manifested that the constructed fluorescence sensor based on $\mathbf{H L}-\mathbf{E u}^{3+}$ has an excellent selective response to MP with good sensitivity.

\section{Detection of MP and the mechanism}

Under the optimized condition, the changes of $\mathbf{H L}-\mathbf{E u}^{3+}$ fluorescent were monitored by fluorescence emission spectroscopy with different concentrations of MP $(0.75-20 \mu \mathrm{M})$. As expected, the fluorescence intensity of $\mathbf{H L}-\mathbf{E u}^{3+}$ at $617 \mathrm{~nm}$ gradually decreased with increasing MP concentration (Fig. 4(A)), and accurate change monitoring of the fluorescence intensity was realized in the presence of MP as Fig. 4(B) showed. The HL-Eu $\mathbf{H}^{3+}$ sensor exhibited a linear response toward the concentration of MP $(0.75-20 \mu \mathrm{M})$, and the fitting linear equation was expressed as $y=0.422 x-0.0181$ with a linear relative coefficient of $R^{2}=$ 0.9944. Furthermore, we also compared our assay with other reported methods for the determination of MP (Table S1 $\dagger$ ), and the results showed that our sensor provided lower detection limit for the detection of MP.

Considering the above analysis, the detection mechanism of the fluorescence sensor based on $\mathbf{H L}-\mathbf{E u}^{3+}$ toward MP was displayed in Scheme 2(b). After the addition of $\mathrm{Eu}^{3+}$ into $\mathbf{H L}$ solution, the coordination of $\mathbf{H L}$ with $\mathrm{Eu}^{3+}$ could occurred immediately through four nitrogen atoms and led to the formation of $\mathbf{H L}-\mathbf{E u}^{3+}$ quaternary complex, which can emit strong red fluorescence due to the removal of coordinated water molecules and an intramolecular energy transfer from HL to $\mathrm{Eu}^{3+}$ through the so-called 'antenna effect'. When MP was added into the system of $\mathbf{H L}-\mathbf{E u}^{3+}$, it could bind with $\mathrm{Eu}^{3+}$ and form a more stable complex because of the stronger nucleophilicity, leading to the obvious decrease of the fluorescence intensity at $617 \mathrm{~nm}$. This selective binding behavior of $\mathrm{Eu}^{3+}$ also resulted in the release of free HL ligand, and the fluorescence of HL at $460 \mathrm{~nm}$ increased. By employing the fluorescent $\mathbf{H L}-\mathbf{E u}^{3+}$ as the sensor, the specific and sensitive detection for MP was realized and the detection limit reached down to $95 \mathrm{nM}$ with $\mathrm{LOD}=3 \sigma / S$.

\section{Detection of MP in real samples}

To demonstrate the feasibility of the present method for selective probing MP in real samples, different concentrations of MP in the spiked pond water and pear juice samples were determined and the results were listed in Table 1 . It can be seen that good recoveries ranging from $96.23 \%$ to $106.62 \%$ were obtained and the RSD were less than $4.0 \%$ for all indicating that the present method is reliable and applicable for MP assay in environmental and food samples.

\section{Conclusions}

In summary, a lanthanide complex sensor $\mathbf{H L}-\mathbf{E u}^{3+}$ based on aromatic cyclic polyamine ligand was constructed by modifying the structure of 4-hydroxybenzlidene imidazolinone (HBI) with 
nitrogen-containing heterocyclic 1,10-phenanthroline. In this system, the competition coordination of $\mathbf{M P}$ and $\mathbf{H L}$ for $\mathrm{Eu}^{3+}$ transformed the fluorescence and established a fluorescence

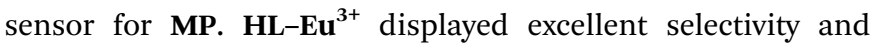
sensitivity toward MP detection, and the detection limit reached $95 \mathrm{nM}$. At the same time, it showed good recovery performance in actual pond water and pear juice samples, indicating that the sensor has the potential application for detecting MP in complex real samples.

\section{Conflicts of interest}

There are no conflicts to declare.

\section{Acknowledgements}

We are grateful for financial support from National Natural Science Foundation of China (No. 21876117, U1833124 and U1833202). We also appreciate Analytical \& Testing Centre of Sichuan University for the characterizations.

\section{References}

1 F. Yang, J. R. Wild and A. J. Russell, Biotechnol. Prog., 1995, 11, 471-474.

2 G. Yao, R. Liang, C. Huang, Y. Wang and J. Qiu, Anal. Chem., 2013, 85, 11944-11951.

3 X. Lian and B. Yan, ACS Appl. Mater. Interfaces, 2018, 10, 14869-14876.

4 N. Fahimi-Kashani and M. R. Hormozi-Nezhad, Anal. Chem., 2016, 88, 8099-8106.

5 X. Gao, Y. Zhao, B. Zhang, Y. W. Tang, X. Y. Liu and J. Li, Analyst, 2016, 88, 1105-1111.

6 Q. Tang, X. Wang, F. Yu, X. Qiao and Z. Xu, J. Sep. Sci., 2014, 37, 820-827.

7 L. Tan, W. Li, H. Li and Y. Tang, J. Chromatogr. A, 2014, 1336, 59-66.

8 S. D. Da, F. E. Paiva Silva, F. G. Silva, G. S. Nunes and M. Badea, Pest Manage. Sci., 2015, 71, 1497-1502.

9 H. Ouyang, L. Wang, S. Yang, W. Wang, L. Wang, F. Liu and Z. Fu, Anal. Chem., 2015, 87, 2952-2958.

10 X. Yan, H. Li, Y. Yan and X. Su, Food Chem., 2015, 173, 179184.

11 X. C. Fu, J. Zhang, Y. Y. Tao, J. Wu, C. G. Xie and L. T. Kong, Electrochim. Acta, 2015, 153, 12-18.

12 J. Gong, Z. Guan and D. Song, Biosens. Bioelectron., 2013, 39, 320-323.

13 R. S. Chouhan, A. C. Vinayaka and M. S. Thakur, Anal. Methods, 2010, 2, 924-928.

14 X. Li, D. Zhang, Z. Liu, Y. Xu and D. Wang, Inorg. Chim. Acta, 2018, 471, 280-289.

15 T. Kim, S. B. Maity, J. Bouffard and Y. Kim, Anal. Chem., 2016, 88, 9259-9263.
16 N. Fahimi-Kashani and M. R. Hormozi-Nezhad, Anal. Chem., 2016, 88, 8099-8106.

17 X. Gao, G. Tang and X. Su, Biosens. Bioelectron., 2012, 36, 7580.

18 J. Chang, H. Li, T. Hou and F. Li, Biosens. Bioelectron., 2016, 86, 971-977.

19 A. Barba-Bon, A. M. Costero, S. Gil, F. Sancenón and R. Martínez-Máñez, Chem. Commun., 2014, 50, 13289-13291.

20 X. Wu, Y. Song, X. Yan, C. Zhu, Y. Ma, D. Du and Y. Lin, Biosens. Bioelectron., 2017, 94, 292-297.

21 S. V. Eliseeva and J. C. BãNzli, Chem. Soc. Rev., 2009, 39, 189227.

22 K. Mikami, M. Terada and H. Matsuzawa, Angew. Chem., 2002, 114, 3704-3722.

23 A. T. Bui, M. Beyler, A. Grichine, A. Duperray, J. C. Mulatier, Y. Guyot, C. Andraud, R. Tripier, S. Brasselet and O. Maury, Chem. Commun., 2017, 53, 6005-6008.

24 K. Binnemans, Chem. Rev., 2009, 109, 4283-4374.

25 D. Knapton, M. Burnworth, S. J. Rowan and C. Weder, Angew. Chem. Int. Ed., 2006, 45, 5825-5829; Angew. Chem., 2006, 118, 5957-5961.

26 H. Zhang, X. Hua, X. Tuo, C. Chen and X. Wang, J. Rare Earths, 2012, 30, 1203-1207.

27 J. C. G. Bünzli and S. V. Eliseeva, Lanthanide Luminescence, Springer Series on Fluorescence (Methods and Applications), Berlin, Heidelberg, 2010.

28 C. Piguet, J. C. G. Bünzli, G. Bernardinelli, G. Hopfgartner and A. F. Williams, J. Alloys Compd., 1995, 225, 324-330.

29 S. W. Magennis, S. Parsons and Z. Pikramenou, Chem.-Eur. J., 2002, 8, 5761-5771.

30 A. Casnati, F. Sansone, J. F. Dozol, H. Rouquette, F. O. Arnaud-Neu, D. Byrne, S. Fuangswasdi, M. J. SchwingWeill and R. Ungaro, J. Inclusion Phenom. Macrocyclic Chem., 2001, 41, 193-200.

31 W. J. Wu, H. X. Huang, M. Chen and D. J. Qian, Chin. Chem. Lett., 2015, 26, 343-347.

32 X. B. Sun, X. Z. Jin, W. Pan and J. P. Wang, Carbohydr. Polym., 2014, 113, 194-199.

33 X. B. Gao, J. Yu, N. Li, H. Y. Yin and J. H. Yang, Chin. Chem. Lett., 2007, 18, 1289-1292.

34 D. Mababa, O. Nihal and M. A. Oturan, Chemosphere, 2007, 66, 841-848.

35 F. L. Edwards and P. B. Tchounwou, Int. J. Environ. Res. Public Health, 2005, 2, 430-441.

36 B. Kmellár, P. Fodor, L. Pareja, C. Ferrer, M. A. Martínezuroz, A. Valverde and A. R. Fernandezalba, J. Chromatogr. A, 2008, 1215, 37-50.

37 L. Chen, D. Wu and J. Yoon, ACS Sens., 2017, 3, 27-43.

38 X. Tian, L. Liu, Y. Li, C. Yang, Z. Zhou, Y. Nie and Y. Wang, Sens. Actuators, B, 2018, 256, 135-142. 